\title{
Berenguer y Brito: mujeres poetas cruzando desde el origen el fin de siglo chileno
}

\section{Rodrigo Cánovas}

Pontificia Universidad Católica de Chile

Uno de los proyectos poéticos más ambiciosos del fin de siglo chileno es el texto Naciste pintada, de Carmen Berenguer, publicado en 1999. Cuerpo excedido, siempre en proceso, festivo y letal, construye un espectáculo donde el espacio de la ciudad, de la mujer y de la escritura convergen en una imagen barroca. Sexo y política, mujer e hibridismo cultural, vida y retórica, sostienen un gran mural donde se garabatean las transfiguraciones de la ciudadanía chilena.

El hilo conductor es la casa, que aparece en los títulos de las tres partes de este texto: "Casa cotidiana", donde una voz autobiográfica exhibe escenas posmodernas decadentes de Santiago de Chile; "Casa de la poesía", donde acompañamos a la poeta por su deambular nocturno por Valparaíso, Puerto Lupanar; y finalmente "Casa inmóvil", donde escuchamos las voces testimoniales de prisioneras políticas de la dictadura, encerradas entre cuatro inmundas paredes. En esta ocasión, privilegiaremos las partes 2 y 3 , que contienen alrededor de trescientas páginas, revelando en su volumen una virtualidad lujuriosa, de gruesos y bien delineados contornos.

Instalados en el taller de escritura de la poeta y siguiendo sus pasos nocturnos por los bares, barrios y prostíbulos del puerto de Valparaíso, teniendo como plataforma de lo real sus conversaciones y paseos con escritores amigos en un Encuentro de Poesía en ese puerto; vemos desplegarse ante nuestros ojos un conjunto de apuntes, a manera de bocetos y aguafuertes, de la prostituta Brenda, elegida para ser tocada, husmeada y representada en el escenario de los signos. Berenguer sigue sus pasos con curiosidad, haciendo bocetos de su cuerpo abusado en un lenguaje festivo y grotesco, que da cuenta de la sensorialidad criolla: "bienvenido a este puerto lupanar, donde chilla el dolor del pujo, sino moco, sino gargajo, al dorado siútico el alambique, quiltra" (51). Brenda es la sexualidad que horada el espacio chileno, alter de un lenguaje deseado para abrir la casa a la otredad, donde se traspasan los límites: "La feria hierve cuando se pasea. Y le gritan iSucia! Su cuerpo es asqueado por la imagen de la pureza. Y Brenda les tira el traste" (61).

Se trata de manosear un cuerpo, una imagen, un discurso, para que contenga y haga disparar todo el revés de la casa chilena, aquella asfixiada por una falsa moral familiar, la que ha sido denunciada y representada por la literatura chilena; pero de modo tibio y laxo, faltando el desborde, que proviene de una poesía que engendra relatos, los que trascienden por los acompasados ritmos de la respiración que los acompañan. Más allá de la prosa poética, es un discurso que se extralimita en la constitución de los géneros discursivos, desde la celebración de una sensibilidad: todo es cuerpo, el que muta, lo que lo hace siempre un artificio en acto. 
Insistamos en la singularidad de la representación del puerto y sus actrices. En constante diálogo con otras artes, su discurso está construido con gran diversidad de referencias intermediales, que son explicitadas. Así, colores porteños que evocan los de Tamayo y Siqueiros, y también los cielos de Magritte. Junto con las referencias pictóricas que incluyen lateralmente las pinturas hechas por los artesanos, vendidas en las plazas populares, también se acude a la referencia teatral, al escenario y sus bastidores: "La luz se torna a ratos amarilla y rinconea unas sombras propicias para el devaneo cómplice a la caricia furtiva. La luz de este teatro de la fiesta porteña enciende de colores la danza perpetua de la latinada musical" (83).

¿Quién es Brenda? Una prenda, una vena, un doble de la poeta Berenguer, su anagrama y es también una casa de acogida, pues contiene miserias alegres; y es un cuerpo que contiene voces sociales contextualizadas, que al mismo tiempo que se centran, se disparan centrífugamente. Contiene toda la pobreza, toda la sexualidad femenina, evocando también todas las retóricas sobre el tema, aceptando el naturalismo de Edwards Bello, el realismo intimista de Manuel Rojas, el grotesco ominoso donosiano, para reconocerse plenamente en el neobarroco -en un amplio arco que va desde Sarduy hasta Perlongher- con énfasis en lo social: la identidad del pobre, la reconfiguración de los lúmpenes del alma $-y$ aquí el parentesco directo es con Eltit y Lemebel.

Este fisgoneo de la poeta en el barrio chino, donde transita la prostituta Brenda, cargado de un lirismo salvaje -me disculpan los adjetivos-, se continúa en el libro con una sección donde se superponen relatos de vidas de prostitutas (recortados e interrelacionados) con titulares de la crónica roja, en un ejercicio en que compiten el documento social y el collage artístico, la oralidad y la retórica, el testimonio y la literatura.

Brenda adquiere otro ropaje, apareciendo ahora en las voces de once prostitutas de calle y burdel, cuyas historias han sido recopiladas de entrevistas realizadas por la poeta (no por los detectives, los llamados "tiras" o judiciales) y reacomodadas en un texto que va combinando fragmentos de estas voces individuales, conformando también una voz coral. Escuchemos: "hay de todo, el tranquilo, el degenerado, escandaloso. Yo me pregunto si el hombre no se vuelve degenerado, porque yo tengo un cliente de hartos años y cada vez pide cosas distintas" (Marina 176). Esta serie sociodocumental, donde nuestra poeta traduce los sonidos y el ritmo de la escucha, se cruza con varios titulares de diarios sensacionalistas, que Carmen Berenguer ha tijereteado y dispuesto en la página, a la manera de un Diario Mural de Noticias. Así reza un titular: "FINGIÓ SER PROSTI Y ATRAPÓ LESBIANA", con la siguiente explicación telegráfica: "Porotazo de mujer-policía: aclaró 2 crímenes" (167).

A nivel existencial, los relatos de las prostitutas contextualizan y resitúan los mensajes sensacionalistas de la crónica roja. Ahora bien, a nivel translingüístico, y siguiendo a Bakhtin, ocurre una hibridación, es decir, un traslape de dos conciencias lingüísticas, que no coinciden entre sí. Hay distintos modos de interpretar esta operación. Se podría pensar que los titulares de los periódicos descalifican el mundo de los bajos fondos; mientras que los testimonios de las prostitutas lo redimen desde el drama de la vida cotidiana 
de los pobres. Puede ser: "cuando habían asiladas las cabronas les pegaban a las niñas, no las dejaban salir, les quitaban la ropa. Por ser, en la misma casa donde yo estaba habían hartas, incluso mujeres que hacían abortos; iban las parteras ahí mismo" (Alejandra 178).

Pero también es cierto que el lenguaje sensacionalista, chistoso y denigratorio, aparece adherido a esos cuerpos y constituyen una forma de su representación. "SE SACÓ PANTIES Y ESTRANGULÓ ESPOSO. 'Me tenía pa'la patá y el combo', aseguró a la policía" (178). Si se quiere representar la inmunda vida, entonces hay que cargar con todos los tipos de discurso y hacerlos circular para que choquen entre sí. La tarea del lector consistiría, entonces, en comprender por qué se ríe, por qué se irrita y por qué se emociona con cada ráfaga escrita. Considero, sin embargo, que Carmen tiene mucha fe en el testimonio, más aún si es recogido por una mujer poeta. $Y$ ya no será entonces tanto que ella traduzca y les preste su voz; sino que, a la inversa, todas las otras son las que le devuelven a una experiencia límite, la de rozarse con ellas.

La tercera y última parte del texto, denominada "Casa inmóvil", constituye el registro visceralmente político de la casa chilena, pues es la exhibición de un relato construido con los fragmentos de voces de prisioneras políticas durante los años 80, en tiempos de dictadura en Chile. Así, junto con una serie anterior conformada por fragmentos de relatos de prostitutas, aparece ahora otra serie, la de las mujeres militantes y creyentes en una causa, a las que se le otorga un espacio de escucha. A diferencia del texto de las prostitutas, aquí no hay contrapunto discursivo; solo el invisible y paciente hilado de Carmen Berenguer, que las ayuda a movilizar un tiempo inmóvil.

La poesía aquí retoma el camino de un compromiso político con implicancias éticas. ¿Qué queda de los cuerpos cuando han sido vaciados de utopías, cuando estas les han sido extirpadas? ¿Cómo es posible que demos la espalda a nuestros sueños? A nivel autorial, se produce aquí un regreso a lo reprimido, un viaje de rescate de los fragmentos, con la esperanza de restituir la unidad o al menos, la dignidad de estas mujeres. Las iniciales M.O. nos susurran: "y aunque a nadie le importe hoy en día qué fue de nuestras vidas" (193). Así, la poeta restituye voces perdidas, para que nos acompañen por siempre. En su caso, es una reafirmación de una identidad, un desborde que la lleva a otro centro de su quehacer: los códigos políticos, que engendran conciencias, cuerpos y lenguajes singulares y que nuestra poeta los introduce a golpes, aceptando todas sus contradicciones, poniéndolos junto con otros códigos, como el sexual, que también tiene su lógica discursiva, en este caso, el lenguaje procaz del grotesco festivo.

En resumen, Naciste pintada pone en escena voces, registros de habla y discursos que se mezclan e hibridizan para mostrar un cuerpo social dañado, pero aún con ímpetu de trascendencia.

A modo de suplemento, quisiera esbozar una comparación de este texto de Berenguer, que cruza voces de la calle y de la casa sórdida chilena, privilegiando códigos sociales, políticos y del grotesco festivo; con un poemario escrito alrededor de la misma fecha, Dónde vas, de 1998, de Eugenia Brito, 
donde se ejecuta una ceremonia donde se exhiben los cuerpos mutilados de razas extinguidas construyéndose un altar andino, con un lenguaje barroco que reviste a estos cuerpos de pedrerías y esmaltes.

El texto tiene como referente el suicidio de tres mujeres coyas, las hermanas Quispe, apodadas "las brutas", ocurrido en febrero de 1974, en plena precordillera nortina, a 4.000 metros de altura. Fueron encontradas colgadas a una cuerda firmemente atada a una roca, con sus vestimentas nuevas y sus zapatos lustrados. Junto con ellas, también ahorcados sus perros, más veinticinco corderos degollados. Brito no es la única que ha trabajado esta historia; también hay una obra dramática de Juan Radrigán, varios videos y reportajes. Lo crucial y novedoso en nuestra poeta es la elaboración de una escena, donde tres mujeres autosilenciadas y automutiladas se incluyen como la versión americana del mito occidental sobre el destino trágico y la rebeldía originaria, presente en las fuerzas terrígenas maternas.

Apropiándose solo de pedazos de esta escena realista -la cuerda, los perros, ciertos decires locales acerca de estas endemoniadas-, las tres coyas son incluidas en el repertorio mítico como una versión de las Parcas, hilanderas de la vida; recordemos: una hila en el huso, la otra mide y la tercera corta con tijeras esa vida. Se supone que Zeus les informa del destino de los hombres, estando sobre ellas; pero algunos sostienen que Zeus vive sometido a las Parcas. Nosotros sabemos que en el mundo andino, ellas controlan el flujo vital.

Una esfinge preside a estas coyas suicidas, implacable con toda circunstancia: "Está allí en el desierto gorda serena melancólica / sin más secreto que la muerte". Será a esta esfinge andina a quien se vuelve el yo poético, invocándola para emprender una escritura que raje y mutile: "ah, bébeme / instaura tu sacralidad y déjame si puedes / una dentellada de odio muy fresca y roja / en el pubis" (31). Es la búsqueda de redención y transgresión en un lenguaje que se transfigure en un cuerpo que condense lo americano.

El texto insiste en la instancia de mutilación: un pedazo que falta en el cuerpo, el que hay que restituir o el que hay que habitar desde la construcción de un retablo, de un altar o de una tumba sagrada. Las coyas se funden con la poeta para exhibir un mundo de pérdidas: "El brazo que me falta. / El hambre el hambre el hambre. / No saber cómo es el hambre. Es ciega es sola / pero es total" (21). Cual hacedora, reconstituye la escena trágica con el brillo del artificio barroco, con un lucimiento ancestral de pulidas pedrerías: "Te tallaré como una joya" (61). Imaginamos un proceso de momificación de la parte que no está, pero que se rellena, cuerpo restante que estará allí por siempre, enterrado en la letra y en el paisaje andino, cual momia chinchorro, aquella encontrada recién en el norte chileno pero rellenada hace miles de años. Descubramos ese cuerpo americano: "Ah, demacrado tubo de carne esmaltada en lana" (77).

En el escenario de las enunciaciones ocurre una simbiosis: un yo poético resideña a estas hermanas coyas con su mano que escribe, que se pone en el lugar del cuerpo mutilado; pero también, ya desde antes han sido las mismas coyas suicidas quienes han convertido su muerte en un ceremonial. 
La poeta solo las cubre, abrazándolas, confundiéndose en un solo cuerpo. Así, la escribiente señala: "Mi lápiz insiste en seguirlas, allí están, las turbias, las golosas, / mirando el acontecer, un solo abismo" (25). Y de inmediato, en eco, se escuchan claramente las otras voces: "Yo soy la mano que entierra / la mano que persiste, la que se inscribe piedra / bajo la lluvia / ¿No ves mi altar? Ese que hace tanto denominaron perdido" (123). Yo poético que se hermana con las tres coyas, que se identifica con el acto sacrificial: "La cuerda. Dadme la cuerda. / Quiero tocar sus hilos y recordar con ellos / el seno que me busca" (88).

Es un viaje por los caminos de la Madre Vieja, que también deglute, que repara destruyendo todo. Pero es a esa fuerza devastadora a la que quiere unirse el yo poético, marcada desde el grito, el delirio y la locura y habitada por los demonios.

Los cuerpos coyas aparecen confundidos con las demás materias andinas: el desierto, la nieve, el agua y los cuerpos estelares. Y es en estos cielos, donde se nos señalan Las Tres Marías, piedras coyas que brillan ciegas. El nombre de María aparece incrustado desde su revés: no es el culto mariano, sino una fuerza terrígena más antigua, que observa un mundo caído desde el cementerio celestial andino. Retablo, entonces, donde junto a un altar para cuerpos embalsamados, se disponen y pegan artesanalmente tres puntos estelares. Desde arriba las Marías observan como fragmentos de cielo, como cuerpos devorados: "Las tres Marías que faltan completar a mi brazo / fueron comidas y eso no es un secreto" (27). Habitando una figuración barroca, este paisaje se confunde con la página que lo retoca y lo resemantiza y entonces lo vemos como un cuaderno: "Y las tres marías se fugan de este cielo / Ahora son tres páginas blancas / ciegas, estériles y un poco marchitas" (33). Y cual relámpago en el escenario metafísico de la escritura, vemos también el pulso de Mallarmé, su diseño de la letra en un espacio sagrado.

Brito escribe en mayúsculas: "CHILE AL REVÉS Y ENTERAMENTE A OSCURAS" (117). La escena congelada de un sacrificio de tres cuerpos abandonados por la patria es también el signo de una paseante citadina removida de su espacio vital. Su himno escenifica entonces la situación existencial en el Chile de fin de siglo, defraudado, exhausto y sin marcas. Escuchemos: "a mí también me habían hundido hacía rato / las pocas cultivadas y calvas letras chilenas / y andaba por las calles consumando mi exilio / como una sentenciada, sin deseo, sin odio / sin madre sin palabra sin país sin pasado" (29).

En busca de un destino, la voz poética de Eugenia Brito, reconoce un linaje en las voces suicidas de las locas mujeres mistralianas, enterradas en el luto; en los mudos paisajes de Zurita, que se levantan de la tumba; en los esmaltes barrocos de Sarduy, que convierten el cuerpo en un objeto de adoración. Una ceremonia parca, con un ritmo marcado por precisos cortes de respiración y conjuntamente, un homenaje a los que resta nuestro olvido.

Final abrupto. ¿Cómo cruzar Naciste pintada, de Carmen Berenguer con este Dónde vas? Cual oxímoron, el grotesco festivo de Carmen se contrapone con la resta trágica del sacrificio de Eugenia; a las voces de la calle, 
la liturgia; al cuerpo desbordado de la prostituta, la parquedad del cierre. La paseante bohemia, que transita libremente por puertos y penetra en las cárceles, es sustituida por una andariega de paso trágico, que se desplaza en medio de una naturaleza muda. Ambas testimonian, pero lo hacen en registros opuestos, que yo siento complementarios: el código de las ciencias sociales, con sus registros empíricos (en Carmen) y la antropología, animada por una escena original, en Eugenia. Una se exhibe en constante movimiento metonímico; mientras que la otra se desenvuelve en la condensación. Un cuerpo abierto y abusado, la exuberancia barroca, carne floreada, y el otro, un cuerpo cerrado, expuesto a nuestros ojos con el maquillaje barroco, que lo transfigura en objeto de culto. Dos modos distintos de testimoniar las ansias de trascendencia del ser americano.

\section{Obras citadas}

Bakhtin, Mikhail. The Dialogic Imagination. Holquist, Michael (ed.). Austin/ London: University of Texas, 1981.

Berenguer, Carmen. Naciste pintada. Santiago: Cuarto Propio, 1999.

Brito, Eugenia. Dónde vas. Santiago: Cuarto propio, 1998.

Sarduy, Severo. Escrito sobre un cuerpo. Buenos Aires: Sudamericana, 1969. 